\title{
28 Research Square \\ From the Sea to the Land: Dynamic of the \\ Sargassum Tide Holobiont in the Caribbean Islands
}

Pascal Jean Lopez ( $\square$ pascal-jean.lopez@mnhn.fr)

CNRS Délégation Paris B https://orcid.org/0000-0002-9914-4252

\section{Vincent Hervé}

Max-Planck-Institut for Terrestrial Microbiology

Josie Lambourdière

Centre National de la Recherche Scientifique

Malika René-Trouillefou

Universite des Antilles et de la Guyane

Damien Devault

Centre National de la Recherche Scientifique

\section{Research}

Keywords: Macroalgae, Methanogenic archaea, Sulfate-reducing bacteria, Epibiont, Microbial communities, Nematodes, Ciliates

Posted Date: June 9th, 2020

DOI: https://doi.org/10.21203/rs.3.rs-33861/v1

License: (c) (i) This work is licensed under a Creative Commons Attribution 4.0 International License.

Read Full License 


\section{Abstract}

\section{Background}

Over the last decade, intensity and frequency of Sargassum blooms in the Caribbean Sea and central Atlantic Ocean have dramatically increased, causing growing ecological, social and economic concern throughout the entire Caribbean region. These golden-brown tides form an ecosystem that maintains life for a large number of associated species, and their circulation across the Atlantic Ocean support the displacement and maybe the settlement of various species, especially microorganisms. To comprehensively identify the micro- and meiofauna associated to Sargassum, one hundred samples were collected during the 2018 tide events that were the largest ever recorded.

\section{Results}

We investigated the composition and the existence of specific species in three compartments, namely, Sargassum at tide sites, in the surrounding seawater, and in inland seaweed storage sites. Metabarcoding data revealed shifts between compartments in both prokaryotic and eukaryotic communities, and large differences for eukaryotes especially bryozoans, nematodes and ciliates. Among the most abundant nematodes, we identified various bacterivores in all compartments, suggesting trophic interactions in Sargassum tides. We also found a number of species of interest, including methanogenic archaea, sulfate- and nitrate-reducing bacteria as well as putative pathogens.

\section{Conclusions}

Here we present novel information on the diversity and trophic interactions of the micro- and meiofauna that are associated with Sargassum at tide and storage sites. Such information may help to better understand the ecological consequences of the Sargassum crises, and to develop proper analyses of the Sargassum associated biodiversity that could be important for application purposes such as biogas or fertilizers production, and to local authority for risks assessment.

\section{Background}

Numerous seaweeds, including the benthic and drifting pelagic Sargassum species, are becoming invasive worldwide, creating a potential threat to native species and local resources, and causing a number of economic and health concerns [1]. Over the last decade, the whole Caribbean region and the West coast of Africa were confronted with massive but irregular brown seaweed tides of the Sargassum complex [2]. These holopelagic macroalgae shoals are composed of two common species, namely, $S$. fluitans and S. natans, associated with rarer varieties. The huge biomass of seaweed washed up along coastlines has direct and indirect consequences on beaches and the functioning of near-shore ecosystems [3-5], and a massive influence on the tourist industry and local economies (i.e., the cost of removing and disposing of piled up Sargassum, housing markets, etc.). Sargassum tides can also have a serious health impact, not only because of the toxicity of associated heavy metals and putative 
pollutants, but also through their decomposition that can lead to the production of hydrogen sulfide $\left(\mathrm{H}_{2} \mathrm{~S}\right)$ and ammonia $\left(\mathrm{NH}_{3}\right)$, which are known to affect humans.

Drifting pelagic Sargassum in the Atlantic Ocean constitutes a floating ecosystem serving as a habitat for a number of species. Many of them might be adapted to such ecosystems, and a number of them correspond to endemic species, including Crustaceans, Teleostei, Cnidaria, Mollusca and Protostomia [6, 7]. Marine rafting organisms associated with Sargassum range from primary producers to top predators, and Sargassum serves as feeding and spawning habitats for marine species like sea turtles, seabirds, fish, invertebrates and micro- and macro-epiphytes [8-17]. Zooplankton which can accumulate near Sargassum might feed on periphyton and serve as prey for other pelagic organisms.

Members of the eukaryotic Sargassum epibionts have been described since the early 1970s and correspond to different phyla, including hydrozoans, bryozoans, polychaeta and blue-green algae. Other primary producers such as diatoms have been associated with Sargassum biofilms $[18,19]$. Similarly, prokaryotic endophytic or epiphytic communities associated with marine macroalgae correspond to another fraction of their holobiont and are potentially involved in nutrient uptake, macroalgae spore release and germination, defense against bactericidal pathogens and other competing organisms, reproduction and settlement [20-22]. Exchanges between the holobiont and the surrounding environment have reciprocal impacts, and micro-organisms initially associated with algae growth might also contribute to their degradation processes [21]. More generally, microorganisms are likely to contribute to algae raft formation and maintenance, algae sinking and biodegradation upon beaching [23], and could provide important applications in the isolation of valuable compounds [24]. At molecular level, the bacterial diversity associated with genus Sargassum has been investigated in only a few locations [2528], but neither the bacterial communities at tide sites nor the eukaryotic ones have ever been explored.

Our study aims to investigate the microbial community associated with Sargassum reaching or lying on the beaches along the coastline of two islands from the lesser Antilles, Guadeloupe and Martinique. We used a metabarcoding approach to describe both prokaryotic and eukaryotic diversity. Comparing sequence data from the seaweed-associated fractions to the contiguous waters, we attempted to identify specific OTUs associated with Sargassum. Finally, we also hypothesized that our analyses would provide novel information on species involved in algae biodegradation and putative exotic species associated with Sargassum.

\section{Methods}

Field sampling procedure. Samples were taken at beaching sites mainly along the Atlantic coasts of Martinique and Guadeloupe during the largest tidal events since 2011 (Fig. 1). Sampling was performed at the end of July and in early August 2018 at several beach locations. On most of the sites, the Sargassum seagrass was collected and the excess of seawater was drain-off using a salad spinner. We also collected the seawater surrounding the seagrass. Samples were either taken directly on the beach or in the water within a range of 0 to $20 \mathrm{~m}$ from the shore. As we took samples from various locations, the 
color of the Sargassum varied from site to site, largely depending on the date of its arrival. However, since the macroalgae can rapidly decay when washed ashore, the marine seawater sampled was expected to have already been influenced by the presence of the seaweed. It was particularly visible in the brownish color of the water. In Martinique, we also took samples from four different sites used by the local collectivity to store the Sargassum that had been removed from the coast. All of the samples were put in sterile $50 \mathrm{ml}$ Falcon tubes placed on ice and stored at $-20^{\circ} \mathrm{C}$ upon arrival at the laboratory until the nucleic acids had been extracted. Total environmental DNA was extracted from the filters of each sample using a PowerBiofilm DNA Isolation kit according to the manufacturer's recommendations (MO BIO, Qiagen, CA, USA).

DNA extraction and library preparation. The Sargassum samples were thawed at $4{ }^{\circ} \mathrm{C}$ and then suspended in $50 \mathrm{ml}$ RNase-free $\mathrm{H}_{2} \mathrm{O}$ (Millipore), vortexed and mechanically sonicated in a water bath ( $35 \mathrm{kHz}$ ) for 3 minutes. The latter procedure was repeated three times. Then the microbial fractions present in the supernatant and extracted from the seagrass were filtered through a $0.2 \mu \mathrm{m}$ GTTP Biofilm Type Filter kit (Millipore). The water samples were filtered using the same method. The microbial DNA was extracted using the DNeasy PowerBiofilm Kit (Qiagen) according to the manufacturer's recommendations. The total DNA was then quantified with Quant-it PicoGreen (Invitrogen, Thermo Scientific Fischer Carlsbad, CA, USA) using a CFX96 Real-Time System, C1000 Touch Thermal Cycler Biorad (Biorad, California, USA).

The DNA libraries were prepared using universal primers for the 16S rRNA (16S-515F-Y rRNA: 5'GTGYCAGCMGCCGCGGTAA-3', and 16S-926R: 5'-CCGYCAATTYMTTTRAGTTT-3') or for the 18S rRNA (TAReuk454FWD1: 5'-CCAGCASCYGCGGTAATTCC-3', and TAReukREV3: 5'-ACTTTCGTTCTTGATYRA-3') genes. The DNA amplifications were performed in triplicate in a final volume of $25 \mu \mathrm{l}$ following the Taq Q5 Hot Start High Fidelity DNA Polymerase recommendations (New England Biolabs). For the 16S rRNA amplification, we also added to the amplification reaction $0.4 \mu \mathrm{l}$ of a $10 \mu \mathrm{M}$ of peptide nucleic acid (PNA) clamps [29], specifically designed to match 16S RNA genes from Sargassum plastid (pPNA: 5'AGCTCAACTTCAAAACT-3') and mitochondria (mPNA: 5'- GGCTAGCCTTATTCGTC-3'). The PCR products were checked on agarose gels, purified using Agencourt AMPure XP beads (Beckman Coulter), and quantified using a Qubit dsDNA HS assay kit. The PCR products were then normalized and pooled (2 pools). The libraries were prepared using $1 \mu \mathrm{g}$ DNA from the pools and the Illumina TruSeq Genomic Nano Library Preparation Kit. The supplier's protocols were followed, with the exception of the use of a modified End-Repair mix to avoid production of chimeric constructs, and no PCR cycle was done to finalize the libraries. The resulting libraries were quantified by QPCR and sequenced using a HiSeq 25002 $\times 300$ paired-end run by Fasteris SA (Plan-les-Ouates, Switzerland).

Sequence processing. Amplicons of the 16S and 18S rRNA gene sequences were analyzed independently with the mothur software version 1.41.3 [30], following a standard operating procedure for Illumina MiSeq data [31]. First, contigs were assembled between the read pairs. Then the barcode, primer sequences and low-quality sequences were removed (minimum length of $350 \mathrm{bp}$ and maximum length of $420 \mathrm{bp}$, removing any sequences with ambiguous bases and any sequences with homopolymers longer than 
$8 \mathrm{bp})$. The sequences were then aligned to the SILVA reference database release 132 [32] and preclustered (pre.cluster, diffs $=1$ ). Singletons were excluded, and chimeras were removed with vsearch (Rognes et al., 2016) implemented in mothur. The sequences were then classified using the k-nearest neighbor (knn) algorithm implemented in mothur and the BLASTN search method (cut-off of $80 \%$ ) with the SILVA reference database release 132 and the PR2 database v4.11.1 [33] for the 16S and 18S rRNA gene amplicons, respectively. After classification, nonbacterial, chloroplast, mitochondria (for the $16 \mathrm{~S}$ rRNA gene dataset), noneukaryotic, Sargassum (for the 18S rRNA gene dataset) and unknown (for both $16 \mathrm{~S}$ and $18 \mathrm{~S}$ rRNA amplicons) sequences were excluded. To account for differences in sampling efforts, 28,491 and 53,263 sequences from the $16 \mathrm{~S}$ and $18 \mathrm{~S}$ rRNA gene datasets respectively, were then randomly subsampled from each sample. Finally, operational taxonomic units (OTUs) were generated using the vsearch distance-based greedy clustering algorithm, with an OTU being defined at the $97 \%$ and $99 \%$ sequence similarity level for the 16 S and 18 S rRNA gene reads, respectively.

Diversity and statistical analyses. All the statistical analyses were computed using $\mathrm{R}$ software version 3.6.3. Principal coordinates analyses (PCoA) and constrained analysis of principal coordinates (CAP) were computed based on Bray-Curtis distances with the phyloseq package [34]. The effect of compartments on prokaryotic and eukaryotic community composition was tested by non-parametric permutational multivariate analysis of variance (PERMANOVA), as implemented in the vegan function adonis (permutations = 9999), after checking for homogeneity of group dispersions with the vegan function betadisper [35]. We also used permutation tests for CAP, as implemented in the vegan function anova.cca (permutations $=9999$ ). To test the relationship between the bacterial and eukaryotic community matrices and between microbial community matrices and geographical location, partial Mantel tests were performed using the ecodist package [36], with Pearson correlation coefficient and $10^{6}$ random permutations. To identify OTUs with differential abundances between substrate and medium, we used the ALDEx2 algorithm on the prokaryotic and eukaryotic community matrices after filtering out the OTUs with less than $0.01 \%$ abundance [37]. In this analysis, statistical significance was assessed based on the Wilcoxon rank test with Benjamini and Hochberg's correction to maintain a $5 \%$ false discovery rate. Functional inference of the prokaryotic OTUs was performed with FAPROTAX v1.1 [38]. FAPROTAX outputs were visualized with the pheatmap R package, using Euclidean distances, and the weighted pair group method centroid (WPGMC) as a clustering method.

Phylogenetic analyses. Phylogenetic relationships between the abundant OTUs (> 1\% relative abundance) of three clades, namely Nematoda, Armophorea and Plagiopylea, were investigated. For each clade, we first collected nearly full length 18S rRNA gene sequences from recent studies [39-41] as reference sequences. These sequences were aligned on the Silva SSU database using SINA v1.2.11 [42] and the subsequent alignments were filtered using trimA/v1.2rev59 with the gappyout method [43]. OTU sequences were added to the reference alignments using the -addfragments option of MAFFT v7.310 [44]. Alignments were trimmed and Smart Model Selection [45] was used to determine the best fit evolutionary model based on Akaike Information criterion. Subsequently, maximum-likelihood phylogenetic trees were built with PhyML 3.0 [46]. Branch supports were calculated using a Chi2-based 
parametric approximate likelihood-ratio test (aLRT) [47]. Finally, each tree was visualized and edited with iTOL [48].

\section{Results}

\section{Sampling strategies}

In the present study, we investigated both prokaryotic and eukaryotic diversity associated with Sargassum during the 2018 tide events that were the largest ever recorded. We sampled the coastlines from different islands in the West Indies, corresponding to the Guadeloupe archipelago and the Martinique islands (Figure 1). One hundred samples were collected from the Sargassum seaweeds, the surrounding water of tide sites and Sargassum from inland storage sites. These three types of samples, or compartments, are hereafter named marine-Sargassum (M.Sarg), seawater (SW) and terrestrialSargassum (T.Sarg), respectively. In total, we obtained 22,214 prokaryotic and 17,679 eukaryotic operational taxonomic units (OTUs).

\section{Community structure}

Beta diversity of the Sargassum microbiota was first visualized using unconstrained ordinations, namely principal coordinates analyses (PCOA) (Additional file 1). PERMANOVAs indicated that both the prokaryotic $\left(R^{2}=0.08, P<0.001\right)$ and the eukaryotic $\left(R^{2}=0.09, P<0.001\right)$ communities were significantly different with regard to the three compartments M.Sarg, T.Sarg and SW. This pattern was further investigated using constrained ordinations, namely canonical analysis of principal coordinates (CAP) (Figure 2), and confirmed by permutation tests for CAP $(P<0.001)$. For both the prokaryotic and the eukaryotic communities, the first axis discriminated between M.Sarg and SW, while the second axis discriminated between T.Sarg and both M.Sarg and SW samples (Figure 2). Since a large fraction of variance remained unexplained by the factors investigated in this study, we also examined the relationship between the prokaryotic and eukaryotic dissimilarity matrices. A Mantel test revealed that the community structure of prokaryotes and eukaryotes were strongly correlated $\left(r_{M}=0.43, P<0.0001\right)$, indicating potential biotic associations.

\section{Diversity of Sargassum-associated communities}

The overall prokaryotic diversity associated with the 100 Sargassum-related samples corresponded to 658 bacterial and archaeal families distributed across 350 orders, and 57 phyla. With $2.53 \%$ of the overall diversity, our results report the association between Archaea and Sargassum samples for the first time. When the diversity of the three different kinds of samples were analyzed independently (Figure 3A), we found that the most diverse phyla, which correspond to about $68 \%$ of the diversity, are, in decreasing order, the Proteobacteria, the Bacteroidetes and the Planctomycetes. Although we found slight differences for the terrestrial Sargassum samples, with an increase in the relative diversity of the Firmicutes, the 10 
most represented orders were the same in all three compartments (Additional file 2). With regard to relative abundance (Figure $3 \mathrm{~A}$ ), the most abundant phyla were the Proteobacteria, followed by Bacteroidetes, Cyanobacteria, Spirochaetes and Firmicutes for the marine samples, while for the terrestrial ones they corresponded to Bacteroidetes, Proteobacteria, Planctomycetes, Firmicutes and Acidobacteria (Additional file 2). It should be noted that for the T.Sarg samples, Euryarchaeota phyla was the seventh most abundant one, with $2.08 \%$ of overall abundance.

The eukaryotic diversity spread across 278 orders, with an overall dominance of Opisthokonta in terms of both richness $(24.9 \%)$ and read abundance $(48.9 \%)$, followed by the Alveolata $(22.3 \%$ of richness and $21.4 \%$ of abundance), and the Stramenopiles (20.7\% of richness and $9 \%$ of abundance). The independent analysis of the three compartments revealed differences in both richness of species and abundance (Figure 3B). For the SW samples, the clades presenting the highest number of OTUs were the diatoms (Bacillariophyta), Alveolates corresponding to Dinophyceae, Syndiniales and Oligohymenophorea (Additional file 3). The SW samples' most abundant organisms corresponded to the Alveolata, Opisthokonta and photoautotrophs (Bacillariophyta, Florideophyceae, Ulvophyceae) (Additional file 3, panel A). Analyses of the most diverse clades for the M.Sarg samples showed a large diversity of Opisthokonta with five different phyla (Bryozoa, Arthropoda, Nematoda, Platyhelminthes and Cnidaria) among the twelve most diverse ones (Additional file 3, panel B). The difference in the diversity of the T.Sarg samples that was visible at the highest taxonomic level (Figure 3 ) was also clear at lower taxonomic ranks, with the Nematoda being the most dominant organisms, followed by Rhizaria and Amoebozoa-related OTUs (Additional file 3, panel C). The eukaryotic data revealed a large number of as yet unclassified eukaryotic OTUs in the different compartments. Focusing on the Opisthokonta, we also found strong differences between the compartments, with the Bryozoa dominating the M.Sarg samples, whereas Nematoda represented most of the diversity within the T.Sarg samples (Additional file 4). In fact, Bryozoa were extremely abundant on the surface of the collected Sargassum samples, especially on the M.Sarg ones, and could be observed macroscopically (Additional file 5). The taxonomy of the abundant Nematoda OTUs ( $>1 \%$ relative abundance) was refined using phylogeny and putative trophic groups were inferred following Meldal et al. (2007) classification (Figure 4). We identified 24 OTUs belonging to 5 orders, namely Enoplida, Chromadorida, Monhysterida, Tylenchida and Rhabditida. Among the Monhysterida, we found ten OTUs including seven potentially bacterivore and particularly abundant in M.Sarg. On the contrary, the seven Tylenchida OTUs, all assigned to the genus Halicephalobus, and the four Rhabditida OTUs were mainly present in T.Sarg samples. Besides bacterivores, we also identified nematodes described as algivore-omnivore-predator, entomopathogen and vertebrate parasites.

\section{Compositional analysis revealed Sargassum-specific associated OTUs}

To analyze the differential abundance of OTUs between the three compartments, we applied the ALDEx2 algorithm. Regarding what we call here the "substrate effect", which is the comparison between the surrounding seawater and the marine Sargassum per se, we identified 68 prokaryotic and 30 eukaryotic 
OTUs with differential abundance (Figure 5A-B). For the prokaryotes, the surrounding seawater harbored 47 OTUs that were significantly more abundant than in the Sargassum samples, including three archaeal OTUs belonging to the Thermoplasmata Marine Group II, an abundant Cryomorphaceae OTU, two abundant members of the Synechococcaceae, a member of the Marinimicrobia clades, and six members of the SAR116 clade group of marine bacterioplanktons (Figure 5A, blue bars). On the other hand, compared to the seawater, the 21 OTUs found to be preferentially associated with the Sargassum samples corresponded to Cyanobacteria, Saprospiraceae, or one Planctomycetes clade OM190 (Figure $5 \mathrm{~A}$, brown bars). In the case of the eukaryotes, the 20 OTUs that were significantly associated with the surrounding seawater corresponded to Dinophyceae, Chlorophyta Cryptophyceae, Prymnesiales, Bacillariophyceae, one of the Demospongiae class, one Teleostean fish (probably from the Serranidae family), and one from the Thraustochytriaceae family (heterotrophic fungus-like clade of Labyrinthulomycetes) (Figure 5B, blue bars). The 10 OTUs that were significantly more abundant in Sargassum included Bryozoans, Maxillopoda, Dinoflagellata (one Syndiniophyceae and one Dinophyceae), one Hydrozoa of the genus Zanclea, and one flatworm of the Rhabdocoela order (Figure $5 B$, brown bars).

Regarding the "medium effect", corresponding to Sargassum collected on the seashore compared to Sargassum from inland storage sites, we identified 146 prokaryotic and 32 eukaryotic OTUs with differential abundance (Figure 5C-D). Sargassum samples from the beach showed significant enrichment of 93 OTUs prokaryotic OTUs. They contained Saprospiraceae, Flavobacteriaceae, Cyanobacteria, Alphaproteobacteria and Gammaproteobacteria, including the most abundant OTU in our dataset which was assigned to the genus Vibrio, and Planctomycetes (Figure $5 \mathrm{C}$, brown bars). The prokaryotes found to be enriched in terrestrial samples represented 53 OTUs distributed over 9 phyla (Figure 5C, green bars). For the eukaryotes, the marine Sargassum showed significant enrichment in 24 OTUs, Dynophyceae, with some members probably from the genus Amphidinium, Bryozoans, Hydrozoans, Bacillariophyceae, a ciliate from the Stichotrichia subclass, and a Pelagophyceae likely to be the Sargassococcus simulans species (Figure 5D, brown bars). The Sargassum samples from storage sites showed significant enrichment of 8 OTUs, including a flagellated protist of the Colpodellidae order, a nematode that was assigned to the Monhysterida order, a filose amoeba, and one flagellate protist that was included in the Heterokonts (Figure 5D, green bars).

\section{Functional inference of prokaryotic diversity}

In order to investigate the microbial functions associated with the Sargassum-associated samples, we used FAPROTAX to predict the metabolic functions of the prokaryotic taxa and identified 2,831 prokaryotic OTUs ( $12.7 \%$ of the global dataset) that could be functionally assigned to a minimum set of 22 functional groups (Figure 6). The five most abundant groups corresponded to chemoheterotrophy ( 1,260 OTUs; $23.19 \%$ of the abundance), fermentation (314 OTUs; $13.04 \%$ of the abundance), nitrate reduction (71 OTUs; $9.32 \%$ of the abundance), phototrophy (388 OTUs; $6.98 \%$ of the abundance), and respiration of sulfur compounds (404 OTUs; $3.91 \%$ of the abundance) (Figure 6). Intracellular parasites, 
predators or exoparasites, and animal parasites or symbionts, corresponded to a relatively large number of organisms with 491, 263 and 189 OTUs, respectively. Interestingly, other functional groups were specifically abundant in terrestrial samples such as methanogenesis (32 OTUs; $0.21 \%$ ), hydrocarbon degradation (21 OTUs; $0.31 \%$ ) and dark oxidation of sulfur compounds (20 OTUs; $0.09 \%$ ) (Additional file $6)$.

\section{Discussion}

Molecular studies of the microbial communities associated with Sargassum are relatively limited [25-28, 49] and to our knowledge absent from near shore Atlantic coasts. Here, we uncover both the prokaryotes and the eukaryotic communities associated with 100 samples corresponding to Sargassum seaweeds from tide sites, the seawater surrounding stranded Sargassum or near-shore rafts, and to Sargassum seaweeds from inland storage sites.

\section{Specific prokaryotic diversity associated with Sargassum samples}

The prokaryotic communities associated with the Sargassum tide-related samples were dominated by Proteobacteria (39.3\%), Bacteroidetes (30.9\%), Cyanobacteria (7.0\%), Spirochaetes (5.5\%) and Firmicutes (3.7\%). Considering the three different compartments studied here, while the higher taxonomic ranking of diversity and abundance appeared quite similar (Figure 3A), some differences were visible in the order level (Additional file 2). The most abundant families associated with the marine Sargassum samples were the Vibrionaceae (Proteobacteria) (14.18\%), a family of ubiquitous marine bacteria. Within the Flavobacteriaceae (11.23\% of M.Sarg), we identified putative fish (Flavobacterium, 36 OTUs; Tenacibaculum, 3 OTUs) and human (Elizabethkingia, 4 OTUs) pathogens. The third one is the Saprospiraceae (Bacteroidetes) (8.14\% of M.Sarg), a family that might contribute to the degradation of complex macromolecular release (i.e., polysaccharides) from the seaweeds and their associated algae. The fourth family is the Spirochaetaceae (4.83\% of M.Sarg), which was shown to dominate the microbial community associated with corals [50] and contained anaerobic species living in coastal marine sediments [51]. The next most abundant families were the Prolixibacteraceae (4.35\% of M.Sarg), and the Rhodobacteraceae (2.88\% of M.Sarg). Overall, our results show that the bacterial communities, which could be a mix of epiphytes and probably endophytes, associated with tide-associated Sargassum, are distinct from those in the surrounding seawater, confirming findings previously obtained for various macroalgae (for Sargassum sp. see [25, 26, 28]).

Interestingly, even with only nine samples of Sargassum collected from inland storage sites, striking differences were found at the highest taxonomy levels. In T.Sarg, Acidobacteria was the sixth most abundant phylum (4.06\%), whereas these bacteria were barely present in the two other compartments analyzed ( 0.14 and $0.31 \%$ for the SW and M.Sarg, respectively). This phylum has been recognized as one of the most abundant and diverse on Earth, predominantly colonizing soil habitats [52]. The other striking 
difference was for the FBP candidate division, with average abundance of $1.75 \%$ in T.Sarg and below $0.002 \%$ in the other samples. Members belonging to this taxon are known to have the capacity to degrade cellulose and hemicellulose [53] and are potential candidates for algae biomass degradation. At family level, we found the most abundant ones were the Flavobacteriaceae ( $9.31 \%$ of T.Sarg), the Prolixibacteraceae (5.36\% of T.Sarg), and the Halomonadaceae (4.73\% of T.Sarg). Interestingly, the two most abundant species correspond to the genera Cobetia and Halomonas. Some members of this genera were isolated in marine and coastal environments, but also in acid mine drainages which are environments with low $\mathrm{pH}$, high salinity, toxic heavy metals and metalloids [54]. Interestingly, storage sites were shown to present high salinity levels and high concentrations of arsenic, which is bioaccumulated by $S$. fluitans and $S$. natans (Devault et al., unpublished data). The other most widely represented families were the Chitinophagaceae ( $4.21 \%$ of T.Sarg), the Pirellulaceae, which contain ammonia-oxidizing bacteria and bacteria associated with biofilms colonizing microplastics [55] and surface sediments, the Spirochaetaceae (3.57\% of T.Sarg), and Acetobacteraceae (2.96\% of T.Sarg). The most abundant OTU of the latter family was assigned to the genus Acidiphilium, containing aerobic bacteria producing acetic acid. Overall, our results highlight changes in prokaryotic diversity associated with the Sargassum holobiont upon terrestrial storage.

\section{Metabolic predictions of Sargassum-associated microbiota}

To gain insights into the roles of prokaryotic taxa, their putative functions were inferred for 2,831 OTUs. We found that 1,260 OTUs were deemed to be chemoheterotroph, representing $23.2 \%$ of the overall abundance (Figure 6). They belong to several bacterial genera, with the most abundant one being Vibrio, followed in M.Sarg by Reinekea, Desulfomicrobium, Spirochaeta, Polaribacter, Cobetia and Alteromonadaceae. Interestingly, the genus Cobetia harbors strains capable of crude oil degradation and producing biosurfactants [56], while Reinekea members were shown to use numerous molecular weight sugars and algal polysaccharides for growth, and are capable of oxidizing thiosulfate and fermenting under anoxic conditions [57]. The predominant bacteria predicted to perform nitrate reduction corresponds to Vibrio. Due to the complexity of the $\mathrm{N}$ cycle, with numerous possible substrates and product makes, it is difficult to assume the role of these bacteria in this instance, but they may make a significant contribution to $\mathrm{N}$ assimilation, either as free-living bacteria or associated with particles, zooplankton or other eukaryotes [58]. Phototrophy, corresponding mainly to abundant OTUs of the Oxyphotobacteria (Cyanobacteria) class, represented 241 OTUS and $6.9 \%$ of the total abundance. Cyanobacteria have long been described on the surface of Sargassum [59] and might also correspond to symbiotic association across the diverse prokaryotic and eukaryotic lineages present in Sargassum rafts.

When washed ashore, Sargassum will decompose and provoke significant environmental issues and health concerns due to the hydrogen sulfide $\left(\mathrm{H}_{2} \mathrm{~S}\right)$ and ammonia $\left(\mathrm{NH}_{3}\right)$ gas emissions. Functional prediction identified 404 OTUs involved in the respiration of sulfur compounds. These OTUs were assigned to several orders including Thermococcales (1 OTU), Clostridiales (51 OTUs), Desulfarculales (35 OTUs), Desulfobacterales (257 OTUs), Desulfovibrionales (87 OTUs), Desulfuromonadales (3 OTUs) 
and Syntrophobacterales (3 OTUs). We also found OTUs that were not predicted by FAPROTAX but are likely to contribute to the S cycle. These corresponded to the genus Sulfurovum or Sulfurimonas. Some of these prokaryotes, which might originate from sediments on the marine surface layers, may contribute to Sargassum decomposition and hydrogen sulfide emissions. While preliminary studies of the Desulfobacterales family reveal a large number of putative novel species, understanding the diversity of sulfate-reducing microorganisms and sulfur-oxidizing microorganisms associated with the Sargassum decomposition process will require further study. In particular, investigation of the presence of functional S cycling-related genes (see, for example, Pelikan, 2016 \#9032) will be needed. The sulfur cycle is linked to other cycles including carbon, metals and metalloids such as arsenic (As) I [60, 61]. This is of particular interest and another important issue given the large amount of As found in $S$. natans and $S$. fluitans along the coastlines of these islands (Devault et al., unpublished data).

A total of 491 OTUs were predicted to be symbiotic, with parasites or human and animal pathogens, including OTUs assigned to the Coxiellales order (128 OTUs of the genus Coxiella), Rickettsiales and Legionellales (55 OTUs of the genus Legionella). Members of these genera can cause severe disease in humans, and their presence in Sargassum-associated samples needs to be investigated with special care since they could well present potential risks. Coxiella were also shown to correspond to stable symbionts associated with corals [62]. The presence of prokaryotic symbionts and eukaryotic parasites can partially explain the significant correlation observed between prokaryotic and eukaryotic community structures.

In the terrestrial samples (T.Sarg), we found OTUs potentially involved in methanogenesis (Additional file 5) among the archaeal Methanomicrobiaceae, Methanosarcinaceae and Methanococcaceae families. These families are often members of microbial communities involved in methane production from algal biomasses [63]. Due to the anaerobic conditions associated with inland storage sites, especially those sampled which were essentially piles of Sargassum, our findings also suggest putative methanogenesis from Sargassum decomposition. This process could be of great interest in the biomass valorization of Sargassum.

\section{Commonality and differences in eukaryotic diversity}

Several taxonomic investigations devoted to specific classes or to the global eukaryotic communities have revealed the micro- and meiofauna associated with Sargassum spp. [19, 49, 64-67]. The present study reports the largest molecular inventory of eukaryotic species associated with Sargassum.

The largest group found corresponded to the opisthokonts, representing $24.9 \%$ of the total diversity and about half $(48.9 \%)$ of the abundance. With a total of $~ 3,600$ OTUs, our data highlight the significant diversity of metazoans, with considerable differences depending on the Sargassum samples (Additional file 4). With 2,200 OTUs, the surrounding water was dominated, in decreasing order, by Arthropoda, Bryozoa and Annelida (Additional file 3). A contrasting result was found for the M.Sarg samples that were dominated by Bryozoan, Arthropoda, Platyhelminthes, Cnidarian and Nematodes (Additional file 3). Bryozoa, a large group of often calcified aquatic invertebrates [68], which is known to contain abundant 
epibionts on Sargassum species $[15,66]$, were largely present on the surface of the collected Sargassum (Additional file 5). Phylogenetic analyses revealed that among the 490 OTUs assigned to Bryozoan, 438 of them were clustering with Membranipora membranacea (accession: JN680943.1) (not shown), including the most abundant OTU that largely dominates our dataset with $19.6 \%$ of the total abundance. Other previously described eukaryotes associated with Sargassum sp. were found such as Fungi ( 410 OTUs; with putative endophythes of the genus Corollospora or Arthrinium) and Choanoflagellates ( 190 OTUs) $[64,69]$.

Nematodes, which represented the most diverse group of Metazoans (21.4\% of their total diversity), showed striking differences depending on the substrate type. They were largely dominant in terrestrial samples, with $\sim 92 \%$ of the metazoan's abundance. The association between nematodes and floating Sargassum from the Atlantic region was already noted a century ago [70]. While colonization of such usually benthic meiofauna could be the result of accidental encounter, benthic nematode species were found attached to the surface of pelagic or benthic Sargassum spp [71-74]. In our dataset, we found that the most abundant OTUs could be present in the three different compartments, although with potentially specific patterns (Figure 4). Marine Sargassum-associated nematodes belong to the Enoplia and Monhysterida clades that have previously been described in marine habitats and present bacteriovore and algivore-omnivore-predator trophic behaviors $[39,75]$. Stranding and decaying stranded Sargassum along the shore could induce alterations in the structure of the intertidal soft-bottom and help nematode fauna to colonize the macroalgae. On the other hand, Halicephalobus (Tylenchina) and Rhabditidae, which are bacterivores [39], presented exclusive or specific patterns associated with terrestrial sites. Regarding the Halicephalobus OTUs, the best blast hit for Otu00067 and Otu00111 was Halicephalobus mephisto (accession number GQ918144), a bacterivore nematode found a the terrestrial deep subsurface that presented hypoxic conditions and a temperature of $37^{\circ} \mathrm{C}[76]$. Similar conditions are expected to occur in T.Sarg samples.

After the Opisthokonts, the Alveolata were the second most diverse superphylum in our samples, including 1,932 dinophyceae and 1,557 ciliate OTUs, corresponding to $15.4 \%$ and $5.4 \%$ of the total abundance, respectively. Among the ciliates, the Oligohymenophorea, which corresponded to the third most abundant class, with 586 OTUs, were abundant in all sample types (Additional file 3). The Spirotrichea and Plagiopylea were especially present in the seawater samples and the Colpodea in the terrestrial ones (Additional file 3). This latter ciliophoran class is mainly present in terrestrial and semiterrestrial habitats, although there is some evidence of its presence in marine environment surveys $[77,78]$. Among the Oligohymenophorea, some Scuticociliates are known to invade and colonize marine hosts' internal organs and can induce severe systemic infections. For instance, Scuticociliatosis has been reported in a broad range of teleosteans [79-81]. Here, we found a number of OTUs which could be assigned to known causative agents of scuticociliatosis: Pseudocohnilembus persalinus or $P$. longisetus (37 OTUs were assigned to this gender), Uronema marinum (2 OTUs), and Miamiensis avidus (1 OTU), suggesting health concerns or at least surveillance. 
Ciliates are versatile organisms and display considerable functional diversity, including in food webs, acting as predators of bacteria, algae, other protists and even some metazoans. Some ciliates are known to be sensitive to oxic/anoxic conditions [82-85] which can occur upon heavy accumulation of Sargassum on the shoreline. Ciliated protozoans were found to be abundant in mats dominated by sulfide-oxidizing bacteria [86], or in sulfur cycling in marine sediments [87]. Ciliates can also present chemosynthetic symbioses with bacteria and archaea [88], including endosymbionts that are involved in methane metabolism [89]. In particular, members of the Plagiopylea and Armophorea classes correspond to ciliates living in oxygen-depleted habitats, which have been shown to host endosymbiotic methanogens [40, 41, 90-93]. Here, we found a total of 134 OTUs belonging to these two classes of ciliates, with the most abundant OTUs present mainly in SW and M.Sarg samples (Supplementary Figs. 78). Our data suggest oxygen concentration depletion at least in marine tide sites, and that some of these organisms could be involved in methane and/or sulfate cycles along the shore.

The third most abundant supergroup, the Stramenopiles, was largely dominated by Bacillariophyceae, with $\sim 2,000$ OTUs or $\sim 11 \%$ of the total diversity. After the diatoms came the Labyrinthulomycetes, which are protists found as parasites on unicellular phototrophs, green algae, and diatoms, and which present pathogenic behavior towards shell organisms (Additional file 3). More generally, heterotrophic protists are organisms commonly found on seaweed surfaces, and are known to play various roles, including in the consumption of organic materials such as dissolved organic carbon (DOC), released by seaweeds such as Sargassum [94]. Thus, the large diversity of protists found here are likely to make a significant contribution to primary and secondary production and to nutrient cycling in the surf and the swash zones [95].

\section{Identification of Sargassum biomarkers}

We used the ALDEx2 algorithm on the prokaryotic and eukaryotic community matrices to identify abundant OTUs with differential abundance between substrates (SW versus M.Sarg) and media (M.Sarg versus T.Sarg). Interestingly, the OTUs with differential abundance in the M.Sarg samples were Dinophyceae, three unclassified Maxillipoda, and probably copepods, which have often been described as associated with Sargassum sp. [66]; three OTUs corresponding to Bryozoa and probably to the genus Membranipora (see [15]), a hydrozoan of the genus Zanclea that was described as being common on a hydroid assemblage on holopelagic Sargassum from the Sargasso Sea [65], and one OTU of flatworm of the Rhabdocoela order, some of whose species are known to live in association with Sargassum [96]. Among the 24 OTUs differentially expressed in the M.Sarg sites (Figure 5), somewhat remarkably, we found one OTU assigned to a toxic dinoflagellate of the Amphidinium carterae genus, another to Ulvella that are endophytic microalgae, one related to the raphid diatom genus Aneumastus, one OTU with the best BLASTN results as Sargassococcus simulans, an epiphyte on floating Sargassum thallus, isolated in the Sargasso Sea, one to the copepod genus Zaus, which are organisms living in the phytal zone, and five to Hydrozoans (Opisthokonta, Cnidaria), which are also frequently encountered as Sargassum epibionts [66]. 
We also found 21 prokaryotic biomarkers in the M.Sarg samples, including cyanobacteria (4 OTUs) and Saprospiraceae (4 OTUs), which are important in the breakdown of complex organic compound (Figure 6). The M.Sarg samples only showed 4 OTUs that were differentially present in this compartment compared to T.Sarg which had two of the three most abundant OTUs in the whole dataset (a Cyanobiaceae and a Cryomorphaceae). In the terrestrial samples, 11 OTUs were considered as biomarkers, with Saprospiraceae (3 OTUs) and new environmental members of the Rivulariaceae family. Altogether, our data revealed a number of potential new molecular markers associated with Sargassum racks from the Caribbean, with a number of them corresponding to potentially new or poorly described species involved in the trophic food webs at tide sites.

\section{Conclusions}

Our study demonstrates specific micro- and meiofauna depending on the Sargassum samples and identified specific prokaryotic (archeae and bacteria) and eukaryotic biomarkers for marine waters at tide sites, near-shore and beach stranded wracks, and inland storage sites. The description of members of the meiofauna (i.e., ciliates and nematodes) that may play important roles in determining community structures provides a firm grounding for further investigation of algal organic matter decomposition and nutrient transfers between the trophic levels, and emphasizes the need for careful investigation of the entire diversity that contributes to gas production. Based on our results, carefully designed molecular studies with the aim of delivering comparative data analyses can provide effective information on species dispersal via drifting Sargassum, and on biogeographical differences in the Sargassum holobiont.

\section{Declarations}

\section{Availability of supporting data}

The raw data sets generated and/or analyzed during the current study are available on the NCBI Sequence Read Archive (SRA) under the BioProjects PRJNA630532 (16S rRNA genes) and PRJNA630533 (18S rRNA genes).

\section{Competing interests}

The authors declare that they have no competing interests.

\section{Electronic supplementary material}

Additional file 1: Differences in community composition.

Additional file 2: Most diverse (left) and abundant (right) prokaryotic orders 
Additional file 3: Most diverse (left) and abundant (right) eukaryotic clades.

Additional file 4: Richness and abundance within the Metazoa.

Additional file 5: Images showing bryozoa on Sargassum.

Additional file 6: Heatmap of predicted functions based on the FAPROTAX database.

Additional file 7: Phylogenetic tree of ciliates of the Plagiopylea class.

Additional file 8: Phylogenetic tree of ciliates from the SAL (Spirotrichea, Armophorea, Litostomatea) group.

\section{Authors' contributions}

Conceptualization, V.H. and P.J.L.; Methodology, V.H., J.L., M.R.T., D.D. and P.J.L.; Investigation, V.H. and P.J.L.; Writing -Original Draft, V.H., J.L. and P.J.L.; Funding Acquisition, P.J.L.

\section{Acknowledgments}

This work was supported by the Labex DRIIHM, the French "Investissements d'Avenir" program (ANR-11LABX-0010), managed by the ANR and the Human-Environment Observatory Littoral Caraïbe. We also acknowledge the essential financial support of the Agence de l'Environnement et de la Maîtrise de I'Energie (ADEME).

\section{Authors' information}

\section{Affiliations}

Max Planck Institute for Terrestrial Microbiology, Karl-von-Frisch-Strasse 10, 35043 Marburg, Germany

Vincent Hervé

Laboratoire Biologie des ORganismes et Ecosystèmes Aquatiques (BOREA), Muséum National d'Histoire Naturelle, Centre National de la Recherche Scientifique, Sorbonne Université, Institut de Recherche pour le Développement, Université de Caen Normandie, Université des Antilles, 43 rue Cuvier 75005 Paris, France. Josie Lambourdière, Malika René-Trouillefou, Damien Devault \& Pascal Jean Lopez

\section{References}


1. Hu Z-M, Fraser C: Seaweed phylogeography. Adaptation and evolution of seaweeds under environmental change. Springer Netherlands; 2016.

2. Wang MQ, Hu CM, Barnes BB, Mitchum G, Lapointe B, Montoya JP: The great Atlantic Sargassum belt. Science $2019,365: 83-87$.

3. Cabanillas-Teran N, Hernandez-Arana HA, Ruiz-Zarate MA, Vega-Zepeda A, Sanchez-Gonzalez A: Sargassum blooms in the Caribbean alter the trophic structure of the sea urchin Diadema antillarum. PeerJ 2019, 7:e7589.

4. Rodriguez-Martinez RE, Medina-Valmaseda AE, Blanchon P, Monroy-Velazquez LV, Almazan-Becerril A, Delgado-Pech B, Vasquez-Yeomans L, Francisco V, Garcia-Rivas MC: Faunal mortality associated with massive beaching and decomposition of pelagic Sargassum. Mar Pollut Bull 2019, 146:201205.

5. van Tussenbroek BI, Arana HAH, Rodriguez-Martinez RE, Espinoza-Avalos J, Canizales-Flores HM, Gonzalez-Godoy CE, Barba-Santos MG, Vega-Zepeda A, Collado-Vides L: Severe impacts of brown tides caused by Sargassum spp. on near-shore Caribbean seagrass communities. Marine Pollution Bulletin 2017, 122:272-281.

6. Butler JN: Studies of Sargassum and the Sargassum community. Ferry Reach, Bermuda: Bermuda Biological Station; 1983.

7. Laffoley DdA, Roe HSJ, Angel MV, Ardron J, Bates NR, Boyd IL, Brooke S, Buck KN, Carlson CA, Causey B, et al: The protection and management of the Sargasso Sea. (Ocean TgfrotA ed. pp. 44: Sargasso Sea Alliance; 2011:44.

8. Ballard SE, Rakocinski CF: Flexible feeding strategies of juveline gray triggerfish (Balistes capriscus) and planehead filefish (Stephanolepis huspidus) with Sargassum habitat. Gulf and Caribbean Research 2012, 24:31-40.

9. Casazza TL, Ross S: Fishes associated with the pelagic Sargassum complex with a discussion of Sargassum community. Fishery Bulletin 1972, 16:1.

10. Fine ML: Faunal variation on pelagic Sargassum. Marine Biology 1970, 7:112-122.

11. Haney JC: Seabird patchiness in tropical oceanic waters - the influence of Sargassum "reefs". Auk 1986, 103:141-151.

12. Jobe CF, Brooks WR: Habitat selection and host location by symbiotic shrimps associated with Sargassum communities: The role of chemical and visual cues. Symbiosis 2009, 49:77-85.

13. Monroy-Velazquez LV, Rodriguez-Martinez RE, van Tussenbroek BI, Aguiar T, Solis-Weiss V, BrionesFourzan P: Motile macrofauna associated with pelagic Sargassum in a Mexican reef lagoon. J Environ Manage 2019, 252:109650.

14. Parr AE: Quantitative observations on the pelagic Sargassum vegetation of the Western North Atlantic. New Haven: Yale University; 1939.

15. Ryland JS: Observations on some epibionts of gulf-weed, Sargassum natans (L) Meyen. Journal of Experimental Marine Biology and Ecology 1974, 14:17-25. 
16. Weis JS: Fauna associated with pelagic Sargassum in the Gulf Stream. The American Naturalist 1968, 80:554-558.

17. Witherington B, Hirama S, Hardy R: Young sea turtles of the pelagic Sargassum-dominated drift community: habitat use, population density, and threats. Marine Ecology Progress Series 2012, 463:1-22.

18. Carpenter EJ: Diatoms attached to floating Sargassum in the western Sargasso Sea. Phycologia 1970, 9:269-274.

19. Maples RS: The epiphytic diatom flora of 2 Sargassum species. Gulf Research Reports 1984, 7:373375.

20. Egan S, Harder T, Burke C, Steinberg P, Kjelleberg S, Thomas T: The seaweed holobiont: understanding seaweed-bacteria interactions. FEMS Microbiol Rev 2013, 37:462-476.

21. Florez JZ, Camus C, Hengst MB, Buschmann AH: A functional perspective analysis of macroalgae and epiphytic bacterial community interaction. Frontiers in Microbiology 2017, 8:2561.

22. van der Loos LM, Eriksson BK, Falcao Salles J: The macroalgal holobiont in a changing sea. Trends Microbio/ 2019, 27:635-650.

23. de Fouw J, Govers LL, van de Koppel J, van Belzen J, Dorigo W, Sidi Cheikh MA, Christianen MJ, van der Reijden KJ, van der Geest M, Piersma T, et al: Drought, mutualism breakdown, and landscapescale degradation of seagrass beds. Curr Biol 2016, 26:1051-1056.

24. Maximo P, Ferreira LM, Branco P, Lima P, Lourenco A: Secondary metabolites and biological activity of invasive macroalgae of Southern Europe. Marine Drugs 2018, 16:265.

25. Mei X, Wu C, Zhao J, Yan T, Jiang P: Community structure of bacteria sssociated with drifting Sargassum horneri, the causative species of golden tide in the Yellow Sea. Front Microbio/ 2019, 10:1192.

26. Serebryakova A, Aires T, Viard F, Serrao EA, Engelen AH: Summer shifts of bacterial communities associated with the invasive brown seaweed Sargassum muticum are location and tissue dependent. Plos One 2018, 13:e0206734.

27. Susilowati R, Sabdono A, Widowati I: Isolation and characterization of bacteria associated with brown algae Sargassum spp. from Panjang Island and their antibacterial activities. Basic Researches in the Tropical and Coastal Region Eco Developments 2015, 23:240-246.

28. Torralba MG, Franks JS, Gomez A, Yooseph S, Nelson KE, Grimes DJ: Effect of Macondo Prospect 252 Oil on Microbiota Associated with Pelagic Sargassum in the Northern Gulf of Mexico. Microb Ecol 2017, 73:91-100.

29. Fitzpatrick CR, Lu-Irving P, Copeland J, Guttman DS, Wang PW, Baltrus DA, Dlugosch KM, Johnson MTJ: Chloroplast sequence variation and the efficacy of peptide nucleic acids for blocking host amplification in plant microbiome studies. Microbiome 2018, 6:144.

30. Schloss PD, Westcott SL, Ryabin T, Hall JR, Hartmann M, Hollister EB, Lesniewski RA, Oakley BB, Parks DH, Robinson CJ, et al: Introducing mothur: open-source, platform-independent, community- 
supported software for describing and comparing microbial communities. Applied and Environmental Microbiology 2009, 75:7537-7541.

31. Kozich JJ, Westcott SL, Baxter NT, Highlander SK, Schloss PD: Development of a dual-index sequencing strategy and curation pipeline for analyzing amplicon sequence data on the MiSeq Illumina sequencing platform. App/ Environ Microbio/2013, 79:5112-5120.

32. Quast C, Pruesse E, Yilmaz P, Gerken J, Schweer T, Yarza P, Peplies J, Glockner FO: The SILVA ribosomal RNA gene database project: improved data processing and web-based tools. Nucleic Acids Research 2013, 41:D590-D596.

33. Guillou L, Bachar D, Audic S, Bass D, Berney C, Bittner L, Boutte C, Burgaud G, de Vargas C, Decelle J, et al: The Protist Ribosomal Reference database (PR2): a catalog of unicellular eukaryote Small SubUnit rRNA sequences with curated taxonomy. Nucleic Acids Research 2013, 41:D597-D604.

34. McMurdie PJ, Holmes S: Phyloseq: an R package for reproducible interactive analysis and graphics of microbiome census data. PLoS One 2013, 8:e61217.

35. Oksanen J, Blanchet FG, Kindt R, Legendre P, Minchin PR, O'Hara RB, Simpson GL, Solymos P, Stevens $\mathrm{MHH}$, Wagner $\mathrm{H}$ : vegan: community ecology package. R package version 2.3-2.: http://CRAN.R-project.org/package=vegan; 2015.

36. Goslee SC, Urban DL: The ecodist package for dissimilarity-based analysis of ecological data. Journal of Statistical Software 2007, 22:1-19.

37. Fernandes AD, Reid JNS, Macklaim JM, McMurrough TA, Edgell DR, Gloor GB: Unifying the analysis of high-throughput sequencing datasets: characterizing RNA-seq, 16S rRNA gene sequencing and selective growth experiments by compositional data analysis. Microbiome 2014, 2:15.

38. Louca S, Parfrey LW, Doebeli M: Decoupling function and taxonomy in the global ocean microbiome. Science 2016, 353:1272-1277.

39. Meldal BH, Debenham NJ, De Ley P, De Ley IT, Vanfleteren JR, Vierstraete AR, Bert W, Borgonie G, Moens T, Tyler PA, et al: An improved molecular phylogeny of the Nematoda with special emphasis on marine taxa. Mol Phylogenet Evol 2007, 42:622-636.

40. Nitla V, Serra V, Fokin SI, Modeo L, Verni F, Venkata Sandeep B, Kalavati C, Petroni G: Critical revision of the family Plagiopylidae (Ciliophora: Plagiopylea), including the description of two novel species, Plagiopyla ramani and Plagiopyla narasimhamurtii, and redescription of Plagiopyla nasuta Stein, 1860 from India. Zoological Journal of the Linnean Society 2019, 186:1-45.

41. Rotterova J, Bourland W, Cepicka I: Tropidoatractidae fam. nov., a deep branching lineage of Metopida (Armophorea, Ciliophora) found in diverse habitats and possessing prokaryotic symbionts. Protist 2018, 169:362-405.

42. Pruesse E, Peplies J, Glockner FO: SINA: accurate high-throughput multiple sequence alignment of ribosomal RNA genes. Bioinformatics 2012, 28:1823-1829.

43. Capella-Gutierrez S, Silla-Martinez JM, Gabaldon T: trimAl: a tool for automated alignment trimming in large-scale phylogenetic analyses. Bioinformatics 2009, 25:1972-1973. 
44. Katoh K, Standley DM: MAFFT multiple sequence alignment software version 7: improvements in performance and usability. Mol Biol Evol 2013, 30:772-780.

45. Lefort V, Longueville JE, Gascuel O: SMS: Smart Model Selection in PhyML. Mol Biol Evol 2017, 34:2422-2424.

46. Guindon S, Dufayard JF, Lefort V, Anisimova M, Hordijk W, Gascuel O: New algorithms and methods to estimate maximum-likelihood phylogenies: assessing the performance of PhyML 3.0. Syst Biol 2010, 59:307-321.

47. Anisimova M, Gascuel O: Approximate likelihood-ratio test for branches: A fast, accurate, and powerful alternative. Syst Biol 2006, 55:539-552.

48. Letunic I, Bork P: Interactive Tree Of Life (iTOL) v4: recent updates and new developments. Nucleic Acids Res 2019, 47:W256-W259.

49. Kim HM, Jo J, Park C, Choi BJ, Lee HG, Kim KY: Epibionts associated with floating Sargassum horneri in the Korea Strait. Algae 2019, 34:303-313.

50. van de Water JA, Melkonian R, Junca H, Voolstra CR, Reynaud S, Allemand D, Ferrier-Pages C: Spirochaetes dominate the microbial community associated with the red coral Corallium rubrum on a broad geographic scale. Sci Rep 2016, 6:27277.

51. Subhash Y, Lee SS: Description of Oceanispirochaeta sediminicola gen. nov., sp nov., an obligately anaerobic bacterium isolated from coastal marine sediments, and reclassification of Spirochaeta litoralis as Oceanispirochaeta litoralis comb. nov. International Journal of Systematic and Evolutionary Microbiology 2017, 67:3403-3409.

52. Kielak AM, Barreto CC, Kowalchuk GA, van Veen JA, Kuramae EE: The ecology of Acidobacteria: Moving beyond genes and genomes. Frontiers in Microbiology 2016, 7:744.

53. Ventorino V, Aliberti A, Faraco V, Robertiello A, Giacobbe S, Ercolini D, Amore A, Fagnano M, Pepe O: Exploring the microbiota dynamics related to vegetable biomasses degradation and study of lignocellulose-degrading bacteria for industrial biotechnological application. Sci Rep 2015, 5:8161.

54. Kim KK, Lee JS, Stevens DA: Microbiology and epidemiology of Halomonas species. Future Microbiology 2013, 8:1559-1573.

55. Miao LZ, Wang PF, Hou J, Yao Y, Liu ZL, Liu SQ, Li TF: Distinct community structure and microbial functions of biofilms colonizing microplastics. Science of the Total Environment 2019, 650:23952402.

56. Guo P, Cao B, Qiu X, Lin J: Draft genome sequence of the crude oil-degrading and biosurfactantproducing strain Cobetia sp. QF-1. Genome Announc 2018, 6:e01456-01417.

57. Avci B, Hahnke RL, Chafee M, Fischer T, Gruber-Vodicka H, Tegetmeyer HE, Harder J, Fuchs BM, Amann RI, Teeling H: Genomic and physiological analyses of 'Reinekea forsetii' reveal a versatile opportunistic lifestyle during spring algae blooms. Environ Microbio/ 2017, 19:1209-1221.

58. Moisander PH, Shoemaker KM, Daley MC, McCliment E, Larkum J, Altabet MA: Copepod-associated Gammaproteobacteria respire nitrate in the open ocean surface layers. Front Microbiol 2018, 9:2390. 
59. Phlips EJ, Willis M, Verchick A: Aspects of nitrogen fixation in Sargassum communities off the coast of Florida. Journal of Experimental Marine Biology and Ecology 1986, 102:99-119.

60. Edwardson CF, Hollibaugh JT: Metatranscriptomic analysis of prokaryotic communities active in sulfur and arsenic cycling in Mono Lake, California, USA. ISME J 2017, 11:2195-2208.

61. Fisher JC, Wallschlager D, Planer-Friedrich B, Hollibaugh JT: A new role for sulfur in arsenic cycling. Environ Sci Technol 2008, 42:81-85.

62. Hester ER, Barott KL, Nulton J, Vermeij MJ, Rohwer FL: Stable and sporadic symbiotic communities of coral and algal holobionts. ISME J 2016, 10:1157-1169.

63. Klassen V, Blifernez-Klassen O, Wibberg D, Winkler A, Kalinowski J, Posten C, Kruse O: Highly efficient methane generation from untreated microalgae biomass. Biotechnol Biofuels 2017, 10:186.

64. Baker P, Minzlaff U, Schoenle A, Schwabe E, Hohlfeld M, Jeuck A, Brenke N, Prausse D, Rothenbeck M, Brix S, et al: Potential contribution of surface-dwelling Sargassum algae to deep-sea ecosystems in the southern North Atlantic. Deep-Sea Research Part II -Topical Studies in Oceanography 2018, 148:21-34.

65. Calder DR: Hydroid assemblages on holopelagic Sargassum from the Sargasso Sea at Bermuda. Bulletin of Marine Science 1995, 56:537-546.

66. Huffard CL, von Thun S, Sherman AD, Sealey K, Smith KL: Pelagic Sargassum community change over a 40-year period: temporal and spatial variability. Marine Biology 2014, 161:2735-2751.

67. Jacobucci G, Leite F: The role of epiphytic algae and different species of Sargassum in the distribution and feeding of herbivorous amphipods. Latin American Journal of Aquatic Research 2014, 42:353-363.

68. Taylor PD, Waeschenbach A: Phylogeny and diversification of bryozoans. Palaeontology 2015, 58:585-599.

69. Hong JH, Jang S, Heo YM, Min M, Lee H, Lee YM, Lee H, Kim JJ: Investigation of marine-derived fungal diversity and their exploitable biological activities. Mar Drugs 2015, 13:4137-4155.

70. Micoletzky H: Freilebende Nematoden aus den treibenden Tangen der Sargassosee. Mitteilungen des Hamburger Zoologischen Museums und Institutes 1922, 39:1-11.

71. Gerlach SA: Attraction of decaying organisms as a possible cause for pachy distribution of nematodes in a Bermuda beach. Ophelia 1977, 16:151-165.

72. Kim HG, Hawkins LE, Godbold JA, Oh CW, Rho HS, Hawkins SJ: Comparison of nematode assemblages associated with Sargassum muticum in its native range in South Korea and as an invasive species in the English Channel. Marine Ecology Progress Series 2019, 611:95-110.

73. Kito K: Phytal marine nematode assemblage on Sargassum confusum Agardh, with reference to the structure and seasonal fluctuations. Journal of the faculty of science Hokkaido university 1982, 23:143-161.

74. Vranken G, Herman PMJ, Vincx M, Heip C: A reevaluation of marine nematode productivity. Hydrobiologia 1986, 135:193-196. 
75. Smythe AB: Evolution of feeding structures in the marine nematode order Enoplida. Integr Comp Biol 2015, 55:228-240.

76. Borgonie G, Garcia-Moyano A, Litthauer D, Bert W, Bester A, van Heerden E, Moller C, Erasmus M, Onstott TC: Nematoda from the terrestrial deep subsurface of South Africa. Nature 2011, 474:79-82.

77. Gimmler A, Korn R, de Vargas C, Audic S, Stoeck T: The Tara Oceans voyage reveals global diversity and distribution patterns of marine planktonic ciliates. Sci Rep 2016, 6:33555.

78. Schoenle A, Nitsche F, Werner J, Arndt H: Deep-sea ciliates: Recorded diversity and experimental studies on pressure tolerance. Deep-Sea Research Part I-Oceanographic Research Papers 2017, 128:55-66.

79. Wei W, Chen K, Miao W, Yang WT, Xiong J: Pseudocohnilembus persalinus genome database - the first genome database of facultative scuticociliatosis pathogens. Bmc Genomics 2018, 19:676.

80. Whang I, Kang HS, Lee J: Identification of scuticociliates (Pseudocohnilembus persalinus, $P$. longisetus, Uronema marinum and Miamiensis avidus) based on the cox1 sequence. Parasitology International 2013, 62:7-13.

81. Xiong J, Wang GY, Cheng J, Tian M, Pan XM, Warren A, Jiang CQ, Yuan DX, Miao W: Genome of the facultative scuticociliatosis pathogen Pseudocohnilembus persalinus provides insight into its virulence through horizontal gene transfer. Sci Rep 2015, 5:15470.

82. Behnke A, Barger KJ, Bunge J, Stoeck T: Spatio-temporal variations in protistan communities along an $\mathrm{O}_{2} / \mathrm{H}_{2} \mathrm{~S}$ gradient in the anoxic Framvaren Fjord (Norway). Fems Microbiology Ecology 2010, 72:89-102.

83. Forster D, Behnke A, Stoeck T: Meta-analyses of environmental sequence data identify anoxia and salinity as parameters shaping ciliate communities. Systematics and Biodiversity 2012, 10:277-288.

84. Orsi W, Song YC, Hallam S, Edgcomb V: Effect of oxygen minimum zone formation on communities of marine protists. Isme Journal 2012, 6:1586-1601.

85. Parris DJ, Ganesh S, Edgcomb VP, DeLong EF, Stewart FJ: Microbial eukaryote diversity in the marine oxygen minimum zone off northern Chile. Frontiers in Microbiology 2014, 5:543.

86. Aranda CP, Valenzuela C, Matamala Y, Godoy FA, Aranda N: Sulphur-cycling bacteria and ciliated protozoans in a Beggiatoaceae mat covering organically enriched sediments beneath a salmon farm in a southern Chilean fjord. Marine Pollution Bulletin 2015, 100:270-278.

87. Wasmund $K$, Mussmann M, Loy A: The life sulfuric: microbial ecology of sulfur cycling in marine sediments. Environmental Microbiology Reports 2017, 9:323-344.

88. Dubilier N, Bergin C, Lott C: Symbiotic diversity in marine animals: the art of harnessing chemosynthesis. Nature Reviews Microbiology 2008, 6:725-740.

89. Hackstein JHP: (Endo)symbiotic Methanogenic Archaea. Springer International Publishing; 2018.

90. Borrel G, O'Toole PW, Harris HMB, Peyret P, Brugere JF, Gribaldo S: Phylogenomic data support a seventh order of methylotrophic methanogens and provide insights into the evolution of methanogenesis. Genome Biology and Evolution 2013, 5:1769-1780. 
91. Hirakata Y, Oshiki M, Kuroda K, Hatamoto M, Kubota K, Yamaguchi T, Harada H, Araki N: Identification and detection of prokaryotic symbionts in the ciliate Metopus from anaerobic granular sludge. Microbes and Environments 2015, 30:335-338.

92. Holmes DE, Giloteaux L, Orellana R, Williams KH, Robbins MJ, Lovley DR: Methane production from protozoan endosymbionts following stimulation of microbial metabolism within subsurface sediments. Front Microbio/ 2014, 5:366.

93. Vd'acny P, Foissner W: Re-analysis of the 18S rRNA gene phylogeny of the ciliate class Colpodea. Eur J Protistol 2019, 67:89-105.

94. Powers LC, Hertkorn N, McDonald N, Schmitt-Kopplin P, Del Vecchio R, Blough NV, Gonsior M: Sargassum sp. act as a large regional source of marine dissolved organic carbon and polyphenols. Global Biogeochemical Cycles 2019, 33:1423-1439.

95. Lastra M, Lopez J, Neves G: Algal decay, temperature and body size influencing trophic behaviour of wrack consumers in sandy beaches. Marine Biology 2015, 162:221-233.

96. Willems WR, Artois T, Vermin W, Chockaert E: Revision of Trigonostomum Schmidt, 1852 (Platyhelminthes, Typhloplanoida, Trigonostomidae) with the description of seven new species. Zoological Journal of the Linnean Society 2004, 141:271-296.

\section{Figures}


A

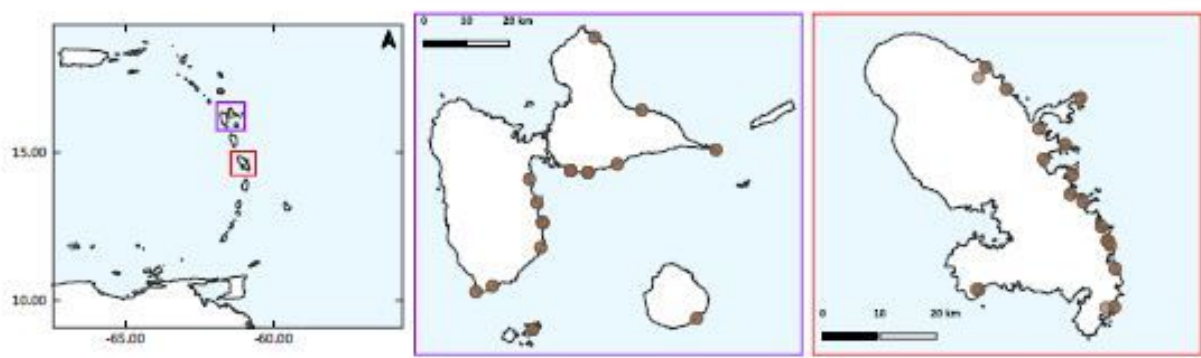

B

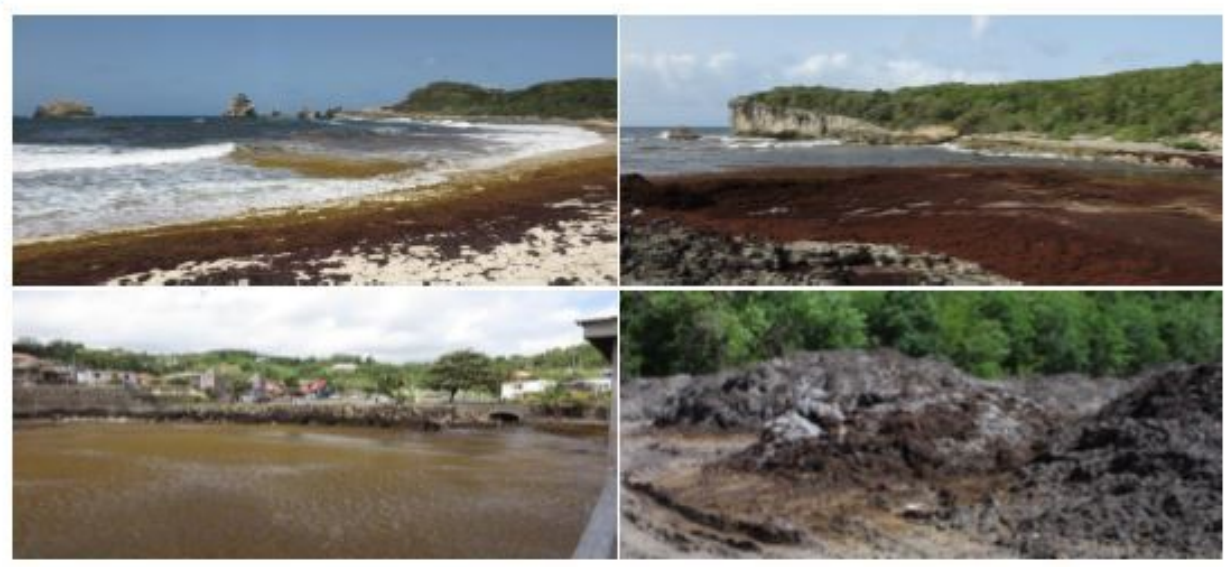

Figure 1: Maps of sampled Sargassum tide sites. The year 2018 corresponded to the biggest tide events ever recorded in the Caribbean region. (A) From left to right, the Caribbean Basin, the Guadeloupe archipelago (violet), and the Martinique island (red). Due to the proximity of the sampled sites, some circles may overlap. (B) Photographs taken during sampling revealing Sargassum accumulated along the shorelines and at one inland-storage site.

\section{Figure 1}

Maps of sampled Sargassum tide sites. The year 2018 corresponded to the biggest tide events ever recorded in the Caribbean region. (A) From left to right, the Caribbean Basin, the Guadeloupe archipelago (violet), and the Martinique island (red). Due to the proximity of the sampled sites, some circles may overlap. (B) Photographs taken during sampling showing Sargassum accumulated along the shorelines and at one inland-storage site. 
A

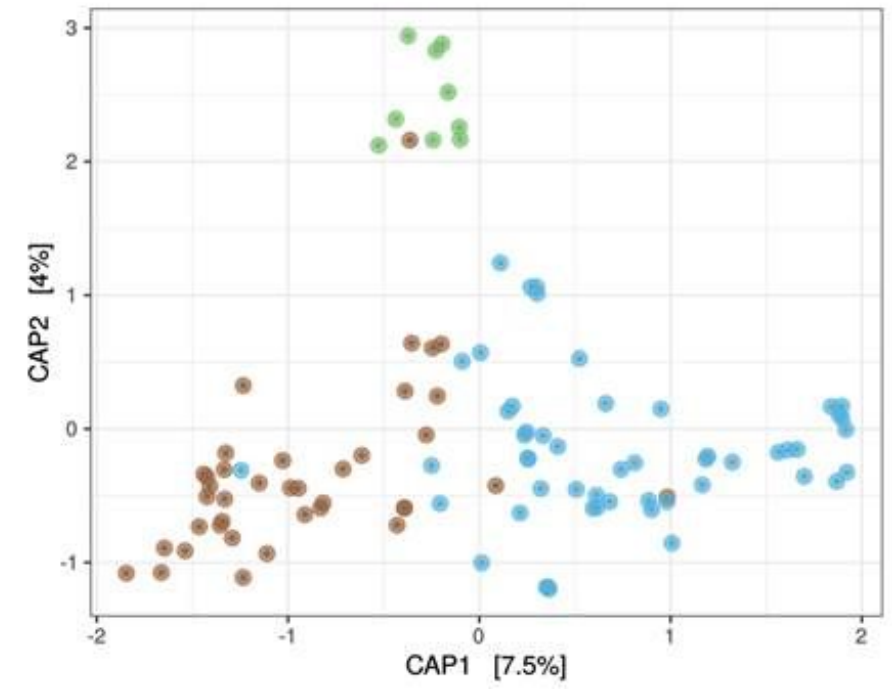

B

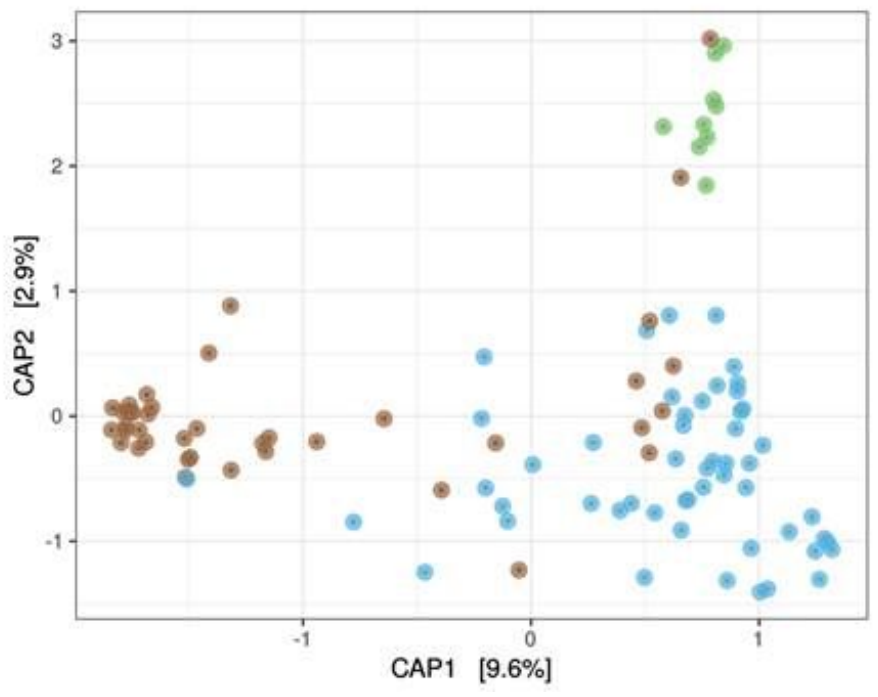

Figure 2

Differences in community composition. (A) Prokaryotic community and (B) Eukaryotic community, revealing significant differences (permutation tests for CAP, $P<0.001$ ) between seawater (SW, in blue), marine Sargassum (M.Sarg, in brown), and terrestrial Sargassum (T.Sarg, in green).

A

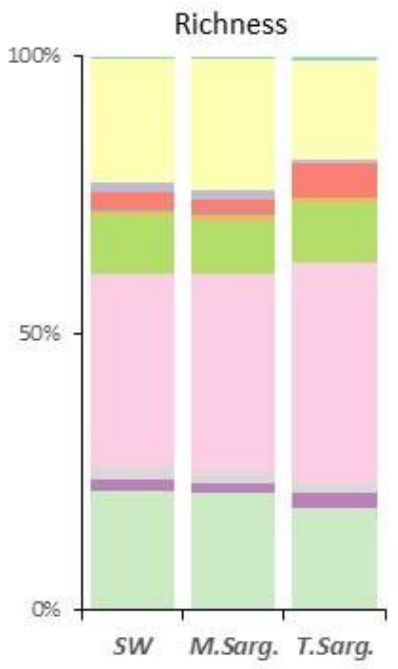

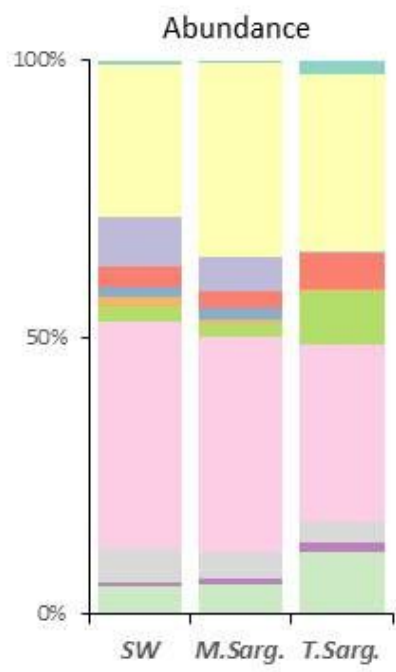

\begin{tabular}{|l|l|l|}
\hline Euryarchaeota & Fusobacteria & Spirochaetes \\
Bacteroidetes & Kiritimatiellaeota & Verrucomicrobia \\
Cyanobacteria & Planctomycetes & Other Bacteria \\
Firmicutes & Proteobacteria & \\
\hline
\end{tabular}

B
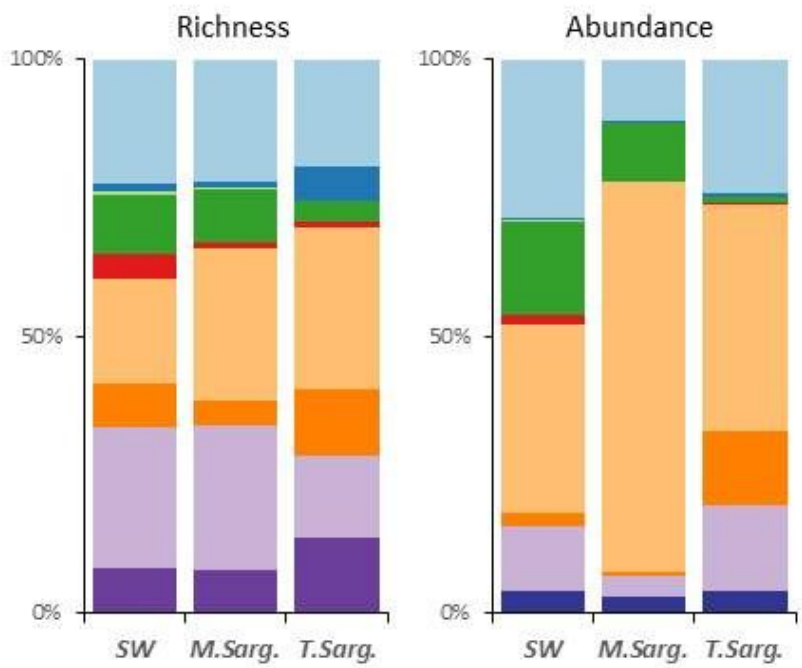

\begin{tabular}{|l|l|l|}
\hline Alveolata & Excavata & \\
Amoebozoa & Hacrobia & Stramenopiles \\
Apusozoa & Opisthokonta & Unclassfied Eukaryotes \\
Archaeplastida & Rhizaria & \\
\hline An
\end{tabular}

\section{Figure 3}

Molecular inventory of the biodiversity associated with Sargassum tides from 100 sampled sites. Differences in the richness and relative abundance of seawater (SW) surrounding marine Sargassum, marine Sargassum (M.Sarg) and terrestrial Sargassum (T.Sarg). (A) Prokaryotic diversity corresponds to 
22,214 OTUs obtained from 2,849,100 reads. (B) Eukaryotic diversity corresponds to 17,679 OTUs obtained from 5,326,300 reads.

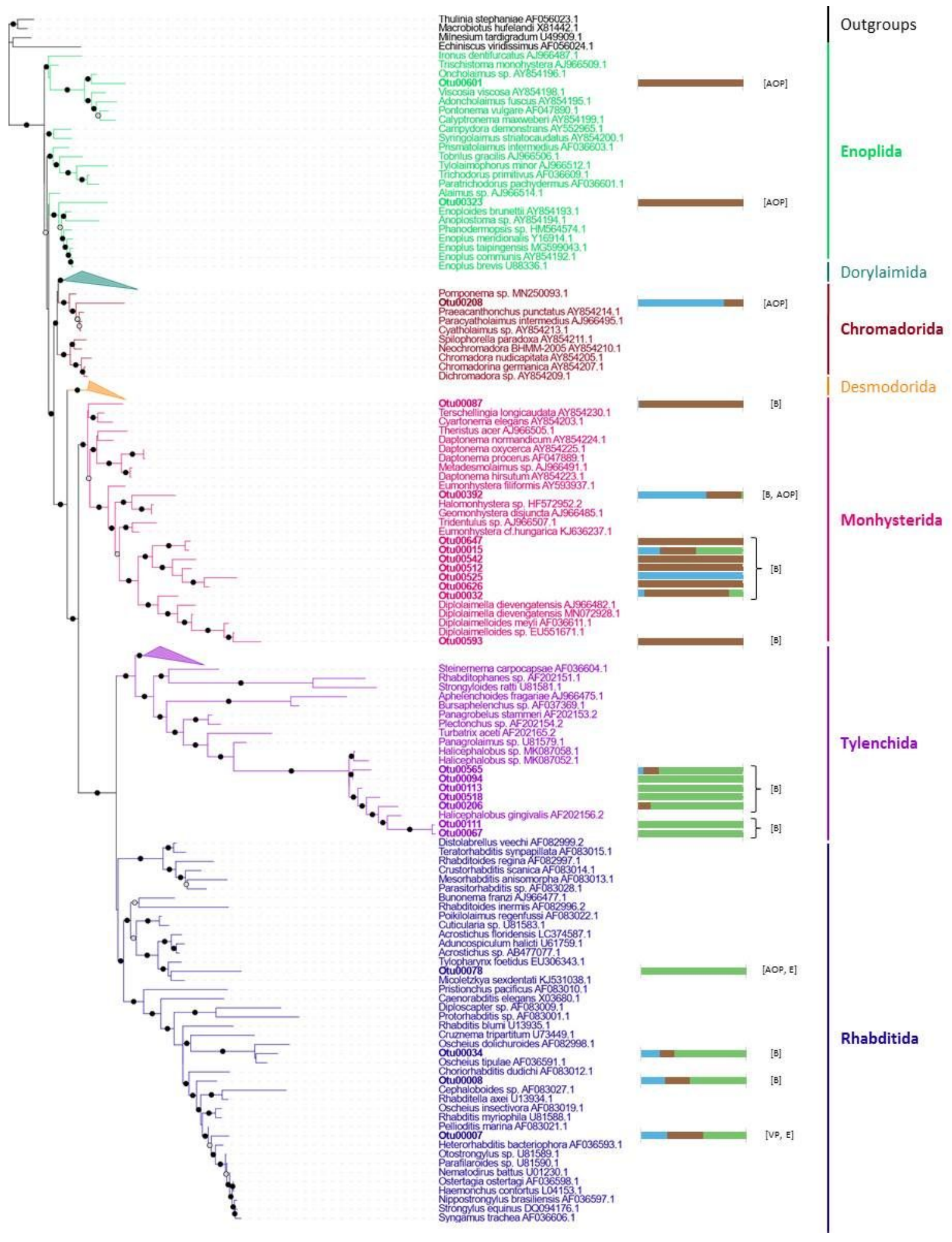

Figure 4

Phylogenetic relationships between the most abundant nematode OTUs associated with Sargassum. The maximum likelihood phylogenetic tree was constructed with PhyML v3.0 using the GTR+G+I model. Branch supports were calculated using a Chi2-based parametric approximate likelihood-ratio test and are 
represented by black circles for values above 0.90 and gray circles for values between 0.7 and 0.89 . OTU sequences are in bold. The horizontal bar plots represent the normalized total abundance of each OTU in the three compartments: SW in blue, M.Sarg in brown, and T.Sarg in green. Putative trophic groups were assigned following recommendations by Meldal et al. (2007): algivore-omnivore-predator [AOP], bacterivore $[\mathrm{B}]$, entomopathogen $[\mathrm{E}]$, and vertebrate parasite [VP].

A

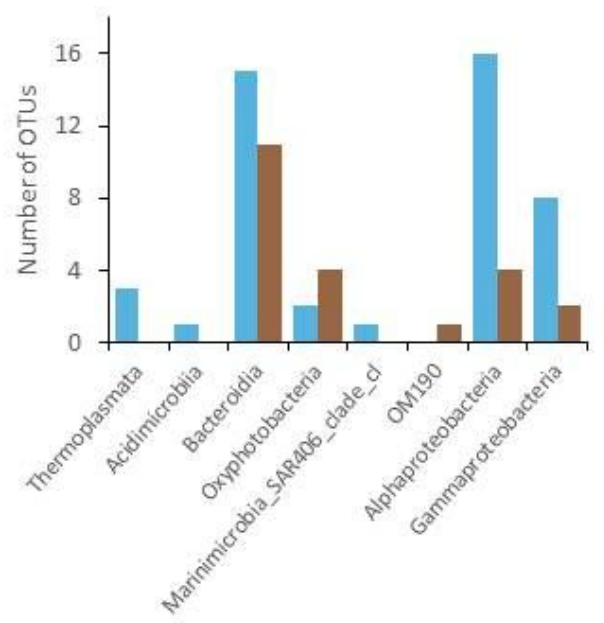

C

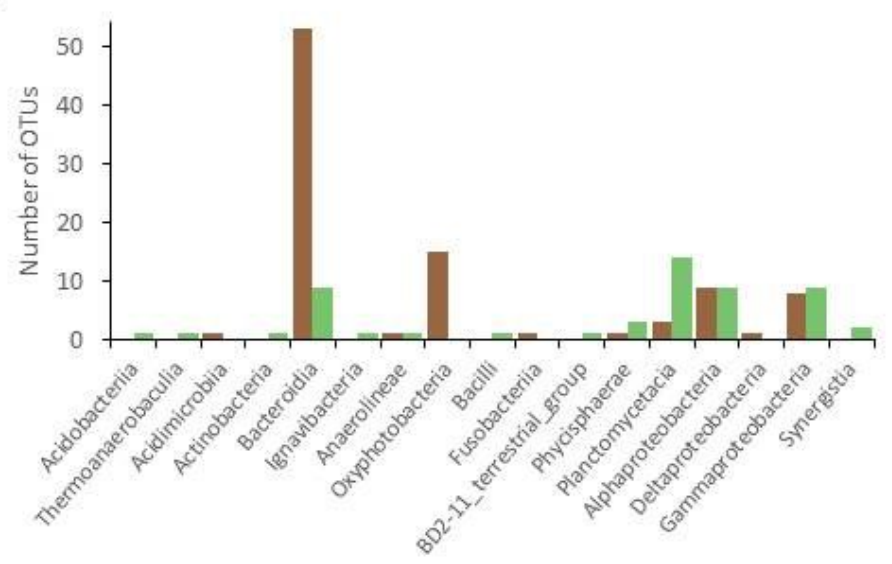

B

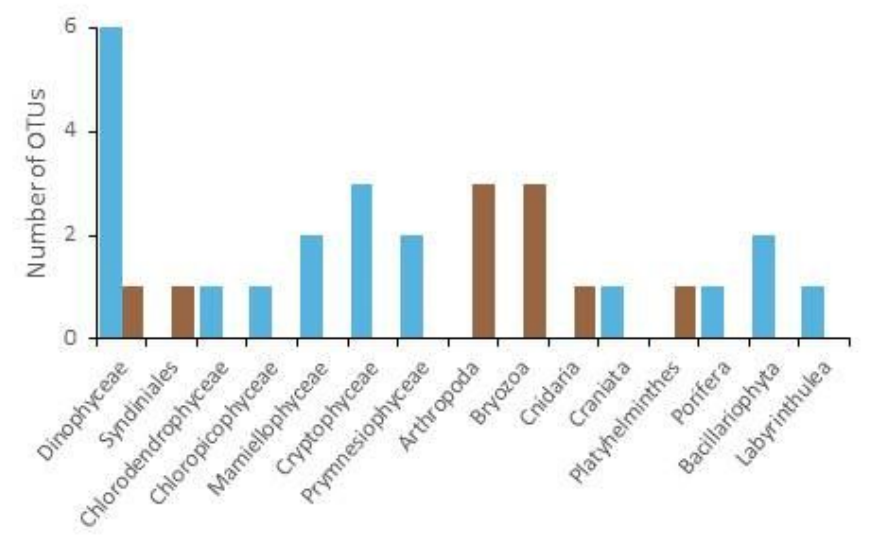

D

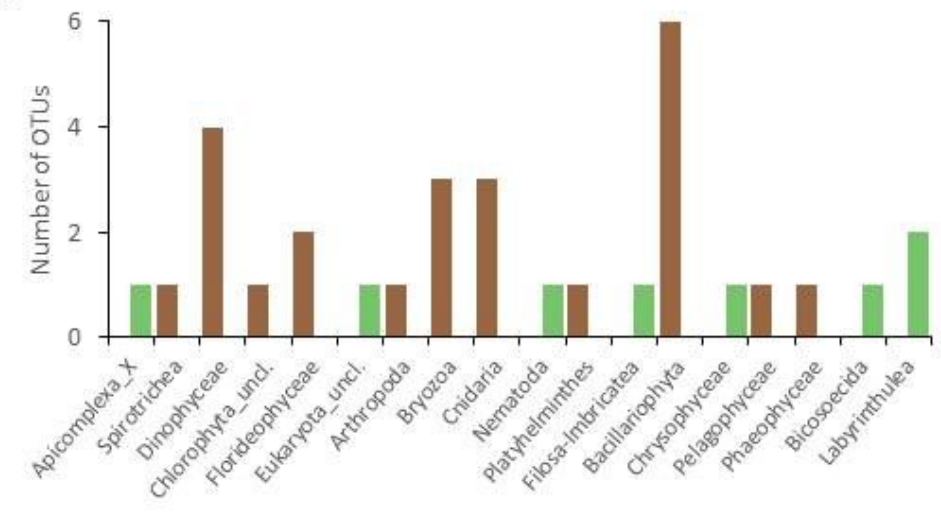

\section{Figure 5}

ANOVA-like differential expression (ALDEx) analysis of the OTUs presenting significant differential abundance for the different Sargassum-associated samples. OTUs that are differentially represented between seawater (blue) or marine Sargassum (brown): (A) Prokaryotic, and (B) Eukaryotic. OTUs that are differentially represented between marine Sargassum (brown) or terrestrial Sargassum (green): (C) Prokaryotic, and (D) Eukaryotic. 


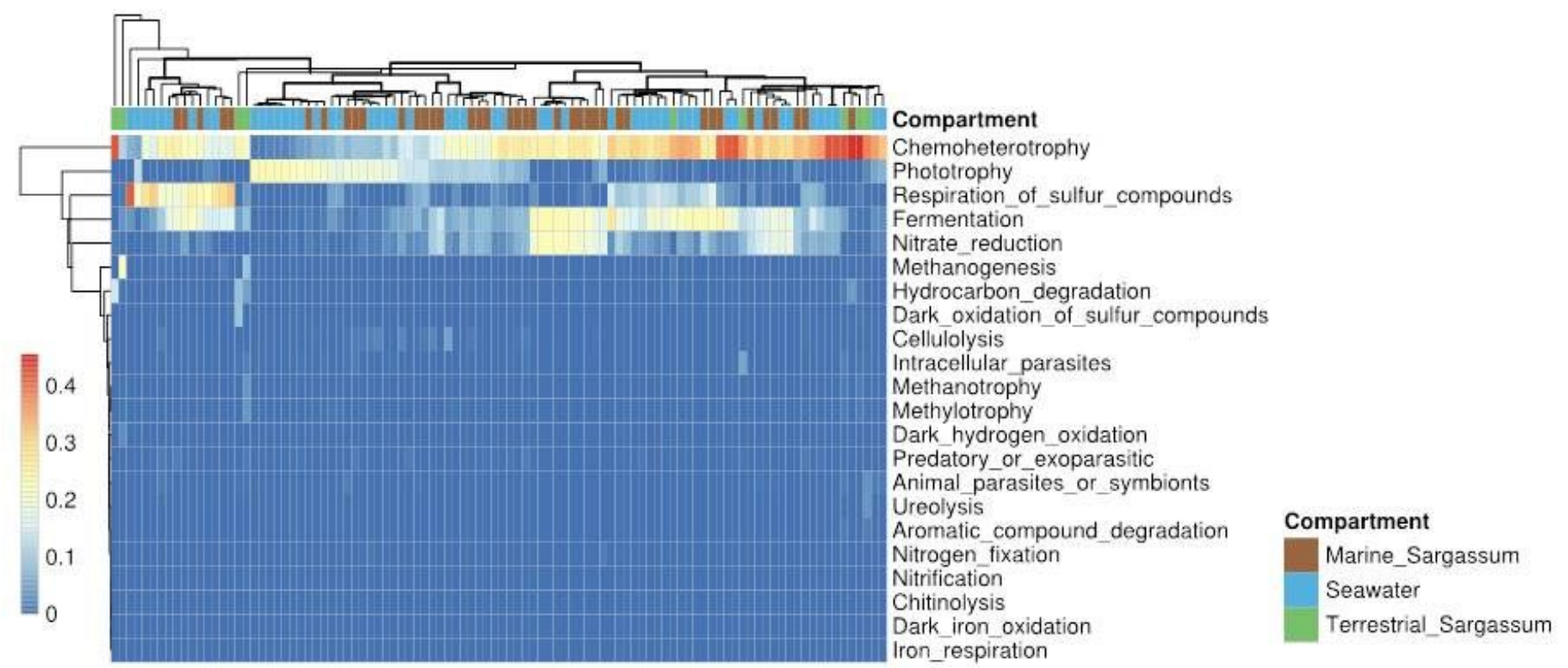

Figure 6

Heatmap of predicted functions based on the FAPROTAX database. The 22 categories presented here correspond to 2,831 prokaryotic OTUs. Data were clustered, with the weighted pair group method centroid (WPGMC) algorithm based on Euclidean distances. The color scale represents the proportion of each predicted function within a sample.

\section{Supplementary Files}

This is a list of supplementary files associated with this preprint. Click to download.

- AddFile8.pdf

- AddFile7.pdf

- AddFile6.pdf

- AddFile5.pdf

- AddFile4.pdf

- AddFile3.pdf

- AddFile2.pdf

- AddFile1.pdf 